\title{
Keefektifan Model Pembelajaran Number Head Together Berbantuan Metode Discovery terhadap Hasil Belajar Matematika
}

\section{Ari Bintari}

PGSD FIP Universitas PGRI Semarang

Jln. Sidodadi Timur No. 24 Dr. Cipto, Kel. Karangtempel, Kec. Semarang Timur, Semarang Email: aribintari@yahoo.com

\begin{tabular}{|c|c|}
\hline ABSTRACT & ABSTRAK \\
\hline $\begin{array}{l}\text { Low mathematics learning outcomes and } \\
\text { student activeness due to lack of effective } \\
\text { learning model in optimizing students' ability and } \\
\text { motivation. The formulation of this research } \\
\text { problem is whether the learning model Number } \\
\text { Head Together (NHT) with the help of effective } \\
\text { discovery method to the result of student } \\
\text { learning class III. This study aims to determine the } \\
\text { effectiveness of the model with the help of the } \\
\text { method of discovery of learning mathematics } \\
\text { class III SDN Mewek. Pre-experimental method } \\
\text { used in this research, which tests, documentation } \\
\text { study, and observation sheet as its instruments. } \\
\text { Based on the results of the final analysis that has } \\
\text { been done visible from the percentage of } \\
\text { mastery learning aiswa show learning without } \\
\text { using learning model NHT as } 5 \text { students who } \\
\text { completed with } 25 \% \text { percent and } 15 \text { students } \\
\text { have not completed with the percentage } 75 \% \text {. } \\
\text { Whereas after being given (posttest) treatment } \\
\text { using NHT learning model and pizza media } \\
\text { fractions that complete } 16 \text { students with } \\
\text { percentage } 80 \% \text { and } 4 \text { students have not } \\
\text { completed with percentage } 20 \% \text {. It is reinforced } \\
\text { by t-test, that students' achievement has been } \\
\text { increased significantly by NHT model. } \\
\text { Keywords: Number Head Together (NHT); } \\
\text { concrete media; fractions }\end{array}$ & 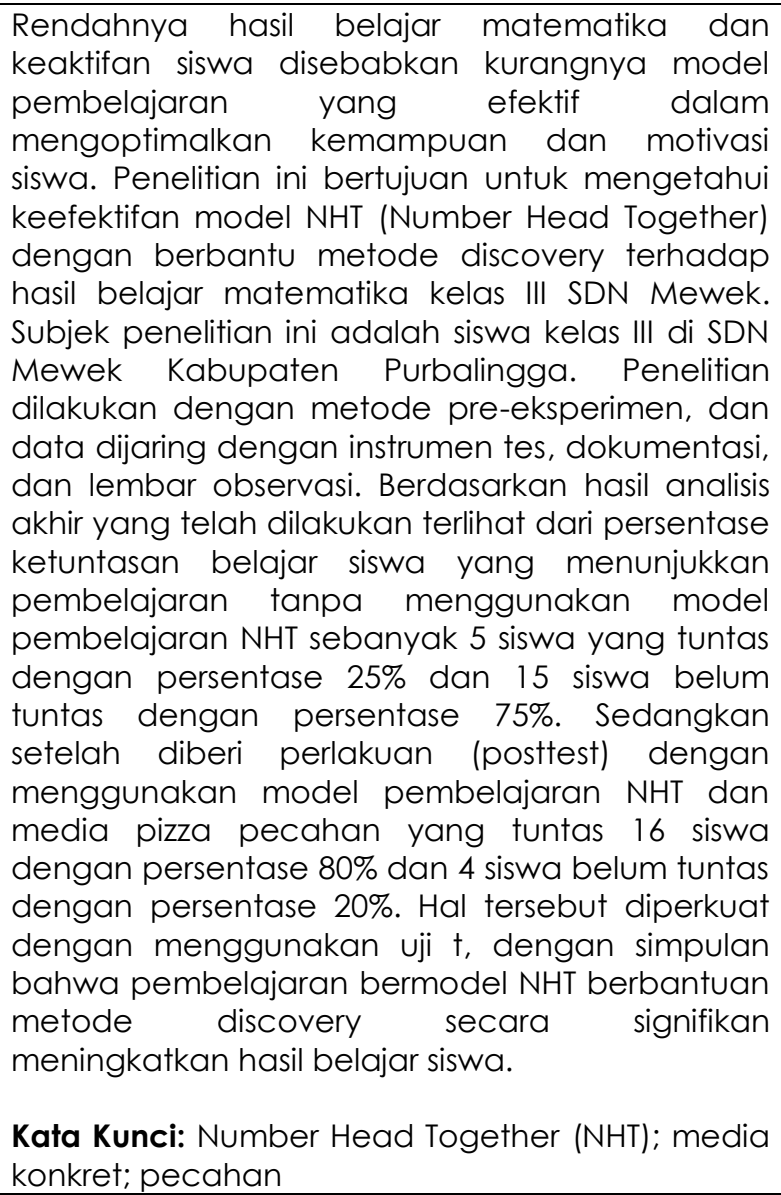 \\
\hline
\end{tabular}

How to Cite: Bintari, A. (2017). Keefektifan Model Pembelajaran Number Head Together Berbantuan Metode Discovery terhadap Hasil Belajar Matematika. Mimbar Sekolah Dasar, 4(3), 218-224. http://doi.org/10.17509/mimbarsd.v4i3.7922.

PENDAHULUAN Pendidikan adalah usaha sadar dan terencana untuk mewujudkan suasana belajar dan proses pembelajaran agar peserta didik secara aktif mengembangkan potensi dirinya untuk memiliki kekuatan spiritual keagamaan, pengendalian diri, kepribadian, kecerdasan, akhlak mulia, serta keterampilan. Pendidikan bertujuan untuk mengembangkan kualitas manusia. Sebagai suatu kegiatan yang sadar akan tujuan, maka dalam pelaksanaannya 
Ari Bintari, Keefektifan Model Pembelajaran Number Head Together...

harus benar-benar memperhatikan kesinambungan setiap jenjang tujuan dalam pendidikan dan pengajaran (Djamarah \& Zain, 2010, p. 42). Pendidikan di sekolah dasar guru masih menggunakan metode ceramah dalam proses pengajarannya, yang mengharuskan siswa menghafal materi yang telah disampaikan, padahal siswa akan mudah lupa jika menggunakan teknik hafalan. Siswa juga kurang memperhatikan, karena proses pembelajaran bersifat teacher centered. Banyak alternatif cara yang dapat digunakan guru untuk meningkatkan daya ingat siswa sehingga mampu menunjang hasil belajar. Mata pelajaran yang biasanya sulit diingat dan dipahami oleh siswa adalah Matematika.

Badan Standar Nasional Pendidikan (2006) menyebutkan bahwa pembelajaran matematika bertujuan (1) memahami konsep matematika, menjelaskan keterkaitan antarkonsep, serta mengaplikasikan dalam pemecahan masalah, (2) memecahkan masalah yang meliputi memahami masalah, merancang model, meyelesaikan model serta menafsirkan solusi yang diperoleh serta mengkomunikasikan gagasan dengan simbol, dan tabel. (3) Menghargai kegunaan matematika dalam kehidupan yaitu memiliki perhatian dan minat dalam belajar matematika. Pada setiap kesempatan, pembelajaran matematika hendaknya dimulai dengan pengenalan masalah yang sesuai dengan situasi.Untuk mengajukan masalah kontekstual secara bertahap siswa dibimbing untuk menguasai konsep matematika. Seringkali siswa sulit dalam menguasai konsep matematika. Hal ini sering membuat hasil belajar siswa menjadi rendah, sehingga siswa kurang berminat dan aktif dalam mempelajari matematika.Apalagi siswa sekarang mudah merasa bosan dan jenuh saat mengikuti kegiatan belajar-mengajar materi matematika tentang pecahan.

Salah satu materi matematika yang sulit dipelajari oleh siswa adalah materi operasi hitung pecahan, hal ini karena pecahan memiliki tingkat kesukaran dan keabstrakan yang tinggi bagi siswa. Dalam materi pecahan siswa dituntut untuk menghitung operasi pecahan baik itu mengurangkan,

menjumlahkan, mengalikan maupun membagikan. Kesulitan siswa dalam mempelajari materi tersebut adalah penyampaian konsep materi yang diberikan oleh guru sulit ditangkap oleh siswa. Hal ini terjadi karena guru tidak menggunakan media kongkret untuk membantu proses pembelajaran.

Selain itu modeldan metode pembelajaran yang kurang bervariasi dalam pembelajaran operasi hitung pecahan juga merupakan penyebab siswa sulit dalam belajar pecahan. Sehingga hasil belajar dan tingkat keaktifan siswa rendah. Guru di sekolah dasar masih menggunakan model ceramah dalam proses pengajarannya, yang mengharuskan siswa menghafalkan materi yang telah disampaikan. Padahal 
siswa lebih mudah lupa jika menggunakan teknik hafalan. Banyak cara yang dapat digunakan guru untuk meningkatkan daya ingat siswa. Model yang digunakan pun masih kurang bervariasi dan menyebabkan siwa menjadi jenuh saat kegiatan belajar-mengajar berlangsung. Terdapat berbagai macam tipe model pembelajaran kooperatif salah satunya adalah model pembelajaran kooperatif type NHT (Numbered Heads Together).

Model pembelajaran kooperatif tipe Numbered Heads Together (NHT) adalah sebuah tipe pembelajaran yang diprakarsai oleh Kagan (1992), juga dikembangkan dalam karya Arends (2000) sebagai alternatif guru dalam membelajarkan siswa. Pada umumnya NHT digunakan untuk melibatkan siswa dalam penguatan pemahaman pembelajaran atau mengecek pemahaman siswa terhadap materi pembelajaran. Sebagian besar aktivitas pembelajaran kooperatif tipe Numbered Heads Together berpusat pada siswa, yakni siswa mempelajari materi pembelajaran sambil berdiskusi untuk memecahkan masalah. Model pembelajaran NHT merupakan salah satu tipe pembelajaran kooperatif yang menekankan pada struktur khusus yang dirancang untuk mempengaruhi pola interaksi serta memiliki tujuan untuk meningkatkan keaktifan dan hasil belajar siswa. Selain dengan model pembelajaran kooperatif tipe Numbered Heads Together peneliti juga menggunakan bantuan pizza pecahan sebagai media pembelajaran agar peserta didik lebih memahami materi yang telah disampaikan. Dengan model pembelajaran kooperatif tipe Numbered Heads Together berbantuan pizza pecahan diharapkan siswa dapat dengan mudah memahami materi operasi hitung pecahan, dan rasa percaya diri siswa dapat terpupuk sehingga siswa dapat memperoleh hasil belajar yang maksimal. Selain itu siswa juga dituntut untuk berperan aktif dan dapat menemukan sendiri informasi dalam kegiatan belajarmengajar. Hal ini sangat tepat dengan menggunakan metode discovery.

Metode discovery adalah suatu metode dalam proses belajar-mengajar yang memperkenankan siswanya menemukan sendiri informasi yang selama ini secara tradisional biasa diberitahukan atau dicerminkan saja (Suryosubroto, 2008). Metode discovery ini menekankan pentingnya pemahaman atau ide-ide penting terhadap suatu disiplin ilmu, melalui keterlibatan siswa secara aktif dalam proses pembelajaran.

Dari uraian di atas, kombinasi antara model Numbered Heads Together dengan bantuan metode discovery merupakan hal yang jarang dilakukan oleh para praktisi pendidikan (guru) dalam melaksanakan kegiatan pembelajaran di kelasnya. Dengan demikian, penulis menganggap bahwa kombinasi Numbered Heads Together dengan bantuan metode discovery merupakan 
Ari Bintari, Keefektifan Model Pembelajaran Number Head Together...

suatu tool baru dalam praktik pembelajaran.

Paparan latar belakang memberi arah tujuan penelitian, yakni untuk mengetahui efektivitas penggunaan kombinasi model Numbered Heads Together berbantuan metode discovery dalam meningkatkan hasil belajar siswa hingga tercapai ketuntasan belajarnya.

\section{METODE}

Pelaksanaan penelitian ini dilakukan di SDN Mewek. Kelas yang dijadikan penelitian yaitu kelas III dengan jumlah 20 siswa. Metode penelitian yang digunakan adalah metode penelitian eksperimen kuantitatif. Metode penelitian eksperimen adalah metode penelitian yang digunakan untuk mencari pengaruh perlakuan tertentu terhadap yang lain dalam kondisi yang terkendalikan (Sugiyono, 2012). Metode eksperimen merupakan metode yang di dalamnya terdapat pemberian perlakuan (treatment) kepada subjek. Siswa nantinya akan diberi perlakuan (treatment) dalam proses pembelajaran untuk meningkatkan hasil belajar.

Dipilihnya pre-experimental design dalam penelitian ini karena dalam desain ini tidak terdapat kelompok kontrol dan kelompok sampel yang tidak dipilih secara random (Fraenkel \& Wallen, 1993; Ruseffendi, 2006). Pre-experimental design yang digunakan adalah one-group pretest-postest design yang mengukur peningkatan hasil belajar sebelum eksperimen atau treatment disebut pretest $\left(\mathrm{O}_{1}\right)$ dan disebut posttest $\left(\mathrm{O}_{2}\right)$. Perbedaan antara pretest $\mathrm{O}_{1}$ postest $\mathrm{O}_{2}$ yakni $\mathrm{O}_{1}-\mathrm{O}_{2}$ yang diasumsikan merupakan efek dari treatment atau eksperimen (Arikunto, 2010). Dalam penelitian ini dilakukan manipulasi berupa pembelajaran dengan menggunakan model Number Head Together (NHT).

Teknik pengumpulan data yang digunakan peneliti ini adalah tes dan nontes. Teknik tes digunakan untuk mengukur hasil belajar (kognitif) dengan penggunaan model pembelajaran Number Head Together (NHT). Jenis tes dalam penelitian adalah soal pilihan ganda yang diberikan pada pelaksanaan pretest dan posttest dan teknik nontes adalah dokumentasi.

\section{HASIL DAN PEMBAHASAN}

Data hasil penelitian diperoleh dari nilai pretest dan posttest hasil belajar siswa. Nilai pretest dan posttest dinyatakan tuntas jika memenuhi KKM. Adapun kriteria Ketuntasan Kriteria Minimal (KKM) pada mata pelajaran Matematika SDN Mewek yaitu 70. Perhitungan nilai pretest dan posstest setelah diberikkan perlakuan hasilnya berbeda. Berikut tabel nilai pretest dan posttest siswa kelas III SDN Mewek.

Tabel 1. Nilai Pretest dan Posttest

\begin{tabular}{cccc}
\hline Jenis Tes & $\begin{array}{c}\text { Nilai } \\
\text { Tertinggi }\end{array}$ & $\begin{array}{c}\text { Nilai } \\
\text { Terendah }\end{array}$ & $\begin{array}{c}\text { Rata- } \\
\text { rata }\end{array}$ \\
\hline Pretest & 80 & 40 & 58,75 \\
\hline Posttest & 90 & 60 & 76,50 \\
\hline
\end{tabular}


Data penelitian ini diperoleh dari data hasil pretest dan posttest. Nilai pretest diperoleh dari nilai tes siswa sebelum diberi perlakuan menggunakan model pembelajaran Number Head Together dan nilai posttest diperoleh dari nilai tes yang dikerjakan oleh siswa setelah diberi perlakuan menggunakan model pembelajaran Number Head Together. Nilai prestestdan nilai posttest diperoleh dari tes yang diberikan, yaitu berupa soal pilihan ganda yang berjumlah 20 soal dengan alokasi waktu mengerjakan 40 menit.

Perhitungan nilai pretest dan nilai posttest setelah diberi perlakuan hasilnya berbeda. Berikut tabel nilai pretest dan posttest siswa kelas III SD Negeri Mewek. Berdasarkan penelitian dengan melihat Tabel 1 hasil belajar sebelum perlakuan nilai pretest menunjukkan rata-rata sebesar 58,75 terdapat 5 siswa yang sudah mencapai KKM dan 15 siswa belum mencapai KKM, sedangkan hasil belajar sesudah perlakuan nilai posttest menunjukkan rata-rata sebesar 76,50 terdapat 16 siswa yang sudah mencapai KKM dan 4 siswa yang belum mencapai KKM. Dari nilai hasil pretest dan nilai posttest ini menunjukkan bahwa ada peningkatan terhadap hasil belajar siswa sesudah perlakuan dengan rata-rata sebesar $16 \%$.

Tabel 2. Hasil Pengitungan Uji t untuk Pretest

\begin{tabular}{ccccccc}
\hline Subjek & Rata-rata & $N$ & Md & $\sum_{X^{2} d}$ & $t_{\text {hitung }}$ & $t_{\text {tabel }}$ \\
\hline Kelas III SDN Mewek & 58,75 & 20 & 17,75 & 1530 & 83,57 & 1.73 \\
\hline
\end{tabular}

Data hasil pretest dan posttest kemudian dianalisis menggunakan uji $\dagger$ dapat dilihat pada Tabel 4 bahwa rata-rata siswa pada kondisi awal sebelum diberi perlakuan dengan menggunakan model NHT sebesar 58,75 sedangkan rata-rata siswa sesudah diberi perlakuan dengan menggunakan model NHTsebesar 76,50. Dari data analisis uji $\dagger$ diperoleh thitung $=$ 83,57 selanjutnya dibandingkan dengan $t_{\text {tabel }}=1,73$ dengan $\mathrm{db}=20-1$ pada taraf signifikan $5 \%$. Hasil ini menunjukkan bahwa thitung > ttabel yaitu 83,57 > 1,729 maka Ho ditolak dan Ha diterima, sehingga dapat disimpulkan bahwa penggunaan model
Number Head Together dalam mata pelajaran Matematika materi Pecahan Sederhana efektif terhadap hasil belajar siswa kelas III SDN Mewek.

Ketuntasan belajar individual dinyatakan sudah tercapai apabila siswa telah menguasai sekurang-kurangnya $68 \%$ terhadap materi setiap bahasan yang diajukan. Berikut Tabel 3 emberikan gambaran ketuntasan belajar siswa:

\section{Tabel 3. Ketuntasan Belajar Siswa}

\begin{tabular}{ccccc}
\hline & \multirow{2}{*}{$\begin{array}{c}\text { Hasil } \\
\text { No }\end{array}$} & \begin{tabular}{c} 
Tingkat \\
Ketuntasan \\
\cline { 4 - 5 } \cline { 4 - 5 }
\end{tabular} & & \multicolumn{2}{c}{ Persentase } \\
\cline { 4 - 5 } & Minimal & Tuntas & $\begin{array}{c}\text { Tidak } \\
\text { Tuntas }\end{array}$ \\
\hline 1 & Pretest & 70 & 25 & 75 \\
2 & Posttest & 70 & 80 & 20 \\
\hline
\end{tabular}


Ari Bintari, Keefektifan Model Pembelajaran Number Head Together...

Persentase ketuntasan belajar siswa menunjukkan bahwa pembelajaran tanpa menggunakan model Number Head Together sebanyak 5 siswa yang tuntas dengan persentase $25 \%$ dan 15 siswa yang belum tuntas dengan persentase $75 \%$. Kemudian setelah diberi perlakuan dengan menggunakan model Number Head Together, ada 16 siswa yang tuntas dengan persentase 80 dan 4 siswa yang belum tuntas dengan persentase $20 \%$.

Berdasarkan pembelajaran dengan model Number Head Together siswa dapat menemukan informasi sendiri, aktif bertanya dan menjawab pertanyaan yang disampaikan guru maupun siswa lain. Dibuktikan dengan meningkatnya prestasi belajar siswa soal pretest-posttest. Pada hasil Pretest diperoleh nilai rata-rata 58,75 dan hasil posttest diperoleh nilai ratarata 76,50 maka disimpulkan rata-rata posttest telah mencapai KKM yang telah ditentukan (70). Hal tersebut sesuai dengan teori belajar yang disampaikan oleh gagne (Suprijono, 2015, p. 2) yaitu "Perubahan disposisi atau kemampuan yang dicapai seseorang melalui aktivitas". Selain diketahui adanya peningkatan hasil belajar pada aspek kognitif, dan aspek afektif pada penelitian diperoleh hasil perhitungan nilai pre-test yang dilakukan di kelas III SDN Mewek Kabupaten Purbalingga berdistribusi normal karena nilai $L_{0}<$ Ltabel yaitu $0,176<0,198$ dengan $n$ $=20$ dan taraf nyata $a=0,05$. Pada tahap akhir berikutnya dilakukan kembali uji normalitas dengan menggunakan nilai posttest. Berdasarkan perhitungan diperoleh Lo < Ltabel yaitu 0,176 < 0,198, maka $\mathrm{H}_{0}$ diterima sehingga dapat disimpulkan bahwa sampel berasal dari populasi berdistribusi normal.

\section{SIMPULAN}

Berdasarkan hasil penelitian yang dilakukan dapat disimpulkan bahwa model Number Head Together berbantuan metode discovery dalam mata pelajaran matematika materi pecahan sederhana efektif dalam meningkatkan hasil belajar siswa kelas III SDN Mewek, sehingga ketuntasan belajar klasikal dapat dicapai dengan cukup baik.

\section{REFERENSI}

Arends, R. (2000). Learning to teach. Yogyakarta: Pustaka Pelajar.

Arikunto, S. (2010). Prosedur penelitian. Jakarta: PT Rineka Cipta.

Badan Standar Nasional Pendidikan. (2006). Standar isi sekolah dasar/madrasah ibtidaiyah. Jakarta: Badan Standar Nasional pendidikan.

Djamarah, S.B. \& Zain, A. (2010). Strategi belajar mengajar. Jakarta: Rineka Cipta.

Fraenkel, J.C. dan Wallen, N.E. (1993). How to design and evaluate research in education (2nd edition). New York: McGraw-Hill Inc.

Kagan, S. (1992). Cooperative learning. San Juan Capistrano: Kagan Kooperative Learning.

Ruseffendi, E.T. (2003). Dasar-dasar penelitian pendidikan dan bidang eksakta lainnya. Semarang: Unnes Press. 
Sugiyono. (2012). Metode penelitian pendidikan pendekatan kualitatif, kuantitatif, dan R\&D. Bandung: Alfabeta.
Suprijono, A. (2015). Cooperative learning. Yogyakarta: Pustaka Belajar.

Suryosubroto. (2008). Proses belajar mengajar di sekolah. Jakarta: Rineka Cipta. 